\title{
Performance of Hydra Probe and MPS-1 Soil Water Sensors in Topsoil Tested in Lab and Field
}

\author{
Gerhard Kammerer ${ }^{1}$, Reinhard Nolz ${ }^{1 *}$, Marek Rodny ${ }^{2}$, Willibald Loiskandl ${ }^{1}$ \\ ${ }^{1}$ Institute of Hydraulics and Rural Water Management, University of Natural Resources and Life Sciences, \\ Vienna (BOKU), Austria \\ ${ }^{2}$ Institute of Hydrology, Slovak Academy of Sciences (IH SAS), Slovakia, Czechoslovakia \\ Email: reinhard.nolz@boku.ac.at
}

Received 7 July 2014; revised 5 August 2014; accepted 1 September 2014

Copyright @ 2014 by authors and Scientific Research Publishing Inc.

This work is licensed under the Creative Commons Attribution International License (CC BY). http://creativecommons.org/licenses/by/4.0/

(c) (i) Open Access

\begin{abstract}
Soil water sensors are commonly used to monitor water content and matric potential in order to study hydrological processes such as evaporation. Finding a proper sensor is sometimes difficult, especially for measurements in topsoil, where changes of temperature and soil water dynamics occur generally with greater intensity compared to deeper soil layers. We assessed the performance of Hydra Probe water content sensors and MPS-1 matric potential sensors in topsoil in the laboratory and in the field. A common soil-specific calibration function was determined for the Hydra Probes. Measurement accuracy and sensor-to-sensor variation were within the manufacturer specification of $\pm 0.03 \mathrm{~m}^{3} \cdot \mathrm{m}^{-3}$. Hydra Probes can operate from dry to saturated conditions. Sensor-specific calibrations from a previous study were used to reduce sensor-to-sensor variation of MPS-1. Measurement accuracy can be expressed by a mean relative error of $10 \%$. According to the manufacturer, the application range of matric potential readings is from $-10 \mathrm{kPa}$ to $-500 \mathrm{kPa}$. MPS-1 delivered also values beyond this range, but they were not reliable. Sensor electronics of the MPS-1 were sensitive to ambient temperature changes. Beyond instrument effects, field measurements showed substantial temperature-driven fluctuations of soil water content and matric potential, which complicated data interpretation.
\end{abstract}

\section{Keywords}

Water Content, Matric Potential, Temperature

\footnotetext{
${ }^{*}$ Corresponding author.
}

How to cite this paper: Kammerer, G., Nolz, R., Rodny, M. and Loiskandl, W. (2014) Performance of Hydra Probe and MPS-1 Soil Water Sensors in Topsoil Tested in Lab and Field. Journal of Water Resource and Protection, 6, 1207-1219. 


\section{Introduction}

The water cycle is a complex dynamical system that includes hydrological processes in atmosphere, vadose zone, and groundwater environment [1]. Understanding the spatial and temporal dynamics of water and energy transfer across the soil-atmosphere boundary layer is an important issue for hydrological sciences [2]. Generally, there is a close interaction among soil temperature, precipitation, evaporation and soil water [3]. Researchers interested in evaporation and related quantities typically use sensors to measure soil temperature and either water content [2] [4] or matric potential [5], or both quantities [6].

Knowing sensor performance is a prerequisite when selecting a device for a certain application. Substantial properties describing this attribute are measuring range, precision (closeness of repeated measurements under unchanged conditions), accuracy (closeness of measurements of a quantity to that quantity's true value), and temperature range and sensitivity. Sensor characteristics should also be considered when interpreting data. However, finding a proper sensor is sometimes difficult, especially for measurements in topsoil, where temporal changes of temperature and soil water content are greater than that in deeper soil layers [7]. Since sensors are typically tested and evaluated in the lab, another question is how a certain device performs under field conditions.

In this study we assessed the performance of a pair of sensor types for monitoring soil water content and matric potential in a topsoil in the laboratory and on a weighing lysimeter under natural conditions. We selected the well-known Hydra Probe soil moisture sensor (Stevens Water Monitoring System, Inc., Portland, OR, USA) and the MPS-1 water potential sensor (Decagon Devices, Inc., Pullman, WA, USA). The Hydra Probe represents a robust sensor that is used in various fields of applications both permanently installed as handheld device [8]-[12]. Regarding calibration, following approaches exist: A default calibration is provided by the factory and consists of a unique function supposedly being suitable for all soils and all individual sensors of the same type. A soil-specific calibration generates a function with soil-dependent parameter values averaging the behavior of individual sensors. Sensor-specific calibration applies only to a particular sensor and a certain soil.

Several authors studied performance of the Hydra Probe sensor in laboratory, including calibration and temperature effects [13]-[17]. However, there are some inconsistent conclusions. Seyfried et al. [15] indicated that a soil-specific calibration of Hydra Probes is sufficient for most applications. In contrast, Evett et al. [13] found a larger inter-sensor variability in soil, and Vaz et al. [17] reported a coefficient of variation of repeated measurements in core samples of $8.6 \%$, which the authors assumed to arise from sensor electronics and oscillation frequency, probe geometry, and sensitivity to soil heterogeneities and air gaps. Moreover, there is a lack of information about temperature effects in natural conditions, especially regarding diurnal fluctuations of soil temperature and soil water content. The MPS-1 was presumably suitable for measuring matric potential in topsoil due to its design and its attributes, particularly the comparatively large measuring range of $-10 \mathrm{kPa}$ to $-500 \mathrm{kPa}$ [18]. Since default calibration has proven to be improper, sensor-specific calibrations are recommended for the MPS-1 [19] [20]. Furthermore, Malazian et al. [19] reported small and inconsistent temperature effects at a constant matric potential of $-25 \mathrm{kPa}$, which seems insufficient regarding the large measuring range. They also compared measurements from field-installed MPS-1 to tensiometer readings as reference quantities; however, the range of matric potential was only between zero and $-60 \mathrm{kPa}$, and the correlation was not very good. Beyond that, little is known about the performance of MPS-1 in natural conditions, especially regarding temperature sensitivity at small matric potential values.

General questions that are addressed in this study refer to calibration and accuracy, measuring range and temperature effects of HP and MPS-1 in order to enhance data interpretation when using both sensors in topsoil under natural conditions.

\section{Materials and Methods}

Three sensor pairs, each with one Hydra Probe and one MPS-1 (HP-MP), were tested first in the laboratory and afterwards in a lysimeter at the experimental station of the University of Natural Resources and Life Sciences, Vienna (BOKU) in Groß-Enzersdorf, Austria.

\subsection{Sensor Specifications}

The Stevens Hydra Probe measures soil water content $\theta\left(\mathrm{m}^{3} \cdot \mathrm{m}^{-3}\right)$, dielectric permittivity $\varepsilon_{\mathrm{R}, \mathrm{TC}}$ (dimensionless), electrical conductivity EC $\left(\mathrm{S} \cdot \mathrm{m}^{-1}\right)$, and soil temperature $T_{\mathrm{s}}\left({ }^{\circ} \mathrm{C}\right)$ [21]. The main structural components of the 
Hydra Probe are a tine assembly and a body housing all electrical components including a thermistor for measuring soil temperature. The tine assembly consists of a base plate that is $25 \mathrm{~mm}$ in diameter and four $58 \mathrm{~mm}$ long metal rods, whereof three rods form an equilateral triangle around the center rod. The tines serve as wave guides for a 50-MHz-signal that is generated in the probe body. When the tines are pushed into soil material, the probe measures the behavior of an electromagnetic wave in the soil in between the conductors. The probe converts the signal response into the dielectric permittivity [21]. Hydra Probe characteristics according to the manufacturer are indicated in Table 1.

The MPS-1 measures soil matric potential $\psi_{\mathrm{m}}(\mathrm{kPa})$ in the range of $-10 \mathrm{kPa}$ to $-500 \mathrm{kPa}$ (pF 2 to $\mathrm{pF} 3.71$ ). Each sensor consists of two circular ceramic disks with a diameter of $3.2 \mathrm{~cm}$ mounted between a shared circuit board and a perforated stainless steel screen. The sensor measures the water content of the ceramics with a frequency domain principle, and converts it to an analog output signal from $0.5 \mathrm{~V}$ (dry) to $0.8 \mathrm{~V}$ (wet) [18]. When a sensor is installed in soil, the matric potential of the water inside the ceramic disks reaches equilibrium after some time by water uptake or release. Consequently, a relationship between the sensor signal and the matric potential of the surrounding soil can be found. MPS-1 characteristics according to the manufacturer are indicated in Table 2.

\subsection{Data Acquisition}

A telemetry system from Adcon Telemetry GmbH (Klosterneuburg, Austria) was used for data logging and data transmission. So-called Remote Terminal Units (RTUs) collected and transmitted data from Hydra Probes and MPS-1. The logging interval was set to 1 hour. Readings were temporarily stored in another RTU, and transmitted via UHF to a central logger. From there, data were transferred to a server and made available via Internet access [22]. Digital versions of Hydra Probes that output $T_{\mathrm{s}}$ and $\varepsilon_{\mathrm{R}, \mathrm{TC}}$ via SDI-12 protocol were used. Three Hydra Probes were connected to an RTU via an adapter. Three MPS-1 sensors were linked to the telemetry system with a standard interface from Decagon Devices, Inc. The interface supplied the sensors with the required stabilized excitation voltage of $2 \mathrm{~V}$ to $5 \mathrm{~V}$ DC and transmitted the sensor output to an RTU [18].

\subsection{Sensor Calibration}

Generally, a sensor is a device that converts a physical phenomenon into an electrical signal; hence, a calibration function is necessary to convert sensor readings into physical quantities. Usually the parameters of the calibration function are determined by minimizing the deviations between calibrated and real values and by the way optimizing accuracy. Therefore, a proper calibration is expected to increase sensor performance considerably [15] [17] [19]. A sensor-specific calibration takes into account sensor-to-sensor variations usually originating from marginally different sensor materials and electronics. A calibration may also be necessary to compensate temperature sensitivity of sensor electronics.

Table 1. Sensor characteristics of Hydra Probe [21].

\begin{tabular}{cccc}
\hline Quantity & Range & Precision & Accuracy \\
\hline Temperature & $-30^{\circ} \mathrm{C}$ to $36^{\circ} \mathrm{C}$ & & $\pm 0.6^{\circ} \mathrm{C}$ \\
Soil Water Content & & $\pm 0.003 \mathrm{~m}^{3} \cdot \mathrm{m}^{-3}$ & $\pm 0.03 \mathrm{~m}^{3} \cdot \mathrm{m}^{-3}$ \\
Real dielectric permittivity & $0^{\circ} \mathrm{C}$ to $35^{\circ} \mathrm{C}^{\mathrm{a}}$ & $0.5 \%$ & $5 \%$ \\
\hline
\end{tabular}

${ }^{\text {a}}$ Range of temperature correction.

Table 2. Sensor characteristics of MPS-1 [18].

\begin{tabular}{cc}
\hline Quantity & Range/Accuracy/Precision \\
\hline Matric potential range & $-10 \mathrm{kPa}$ to $-500 \mathrm{kPa}$ \\
Accuracy & $\pm 40 \%$ with default calibration \\
Precision & $1 \mathrm{kPa}$ from $-10 \mathrm{kPa}$ to $-100 \mathrm{kPa}$ \\
& $4 \mathrm{kPa}$ from $-100 \mathrm{kPa}$ to $-500 \mathrm{kPa}$ \\
\hline
\end{tabular}


The Hydra Probe requires a soil-specific calibration considering its mineral and organic soil composition [15]. Before converting the raw relative permittivity values $\varepsilon_{\mathrm{R}}$ (dimensionless) of the Hydra Probe into soil water contents $\theta\left(\mathrm{L}^{3} \cdot \mathrm{L}^{-3}\right)$, the readings must be corrected for temperature [15] [21]. The standard function for temperature compensation is [23]

$$
\varepsilon_{\mathrm{R}, \mathrm{TC}}\left(\varepsilon_{\mathrm{R}}, T\right)=1.011 \varepsilon_{\mathrm{R}} /(1.045-0.00225 T),
$$

where $T$ is the temperature in ${ }^{\circ} \mathrm{C}$ and $\varepsilon_{\mathrm{R}, \mathrm{TC}}$ is $t$ the temperature-corrected relative permittivity $\left(\left[\varepsilon_{\mathrm{R}, \mathrm{TC}}\right]=1\right)$.

For the soil-specific calibration we used a standard function of the form

$$
\theta\left(\varepsilon_{\mathrm{R}, \mathrm{TC}}\right)=A \cdot \varepsilon_{\mathrm{R}, \mathrm{TC}}^{0.5}-B
$$

with two parameters $A$ and $B$ to convert the temperature-corrected real dielectric permittivity $\varepsilon_{\mathrm{R}, \mathrm{TC}}$ into soil water content $\theta\left(\mathrm{m}^{3} \cdot \mathrm{m}^{-3}\right)$.

The MPS-1 was tested by Malazian et al. [19] in the lab. They reported a highly nonlinear sensitivity, a large sensor-to-sensor variation, a good consistency of sensor readings, and minor hysteresis and temperature effects. Since the default calibration was inaccurate, they calibrated each sensor specifically in a pressure plate apparatus from $-10 \mathrm{kPa}$ to $-400 \mathrm{kPa}$, which is the only suitable method for that range. For this study we used sensor-specific calibration functions from a previous study (also determined by means of a pressure plate apparatus) [20].

\subsection{Experimental Setup in the Laboratory}

\subsubsection{Inter-Sensor Variability and Sensing Volume of the Hydra Probes}

To assess variations between the three Hydra Probes, $\varepsilon_{\mathrm{R}}$ was measured with three replications in air and tap water with low electrical conductivity $E C=0.03 \mathrm{~S} \cdot \mathrm{m}^{-1}$, eliminating any critical aspects associated with soil. After measuring in air, the sensor rods were slowly moved towards the water table. Since the sensor readings did not change until the tops of the tines contacted the water table (data not shown), it was evident that the electromagnetic field of the sensor did not extend considerably beyond the tines. While slowly immersing the sensor rods in water, the measured dielectric permittivity changed linearly with penetration depth, which is consistent with results of Loiskandl et al. [24]. The readings at full submersion were later used for the sensor-specific calibration.

\subsubsection{Temperature Effects of the MPS-1}

For the MPS-1 Malazian et al. [19] reported small and inconsistent temperature effects at $-25 \mathrm{kPa}$. Since temperature fluctuations of $\psi_{\mathrm{m}}$ were assumed to be larger at small values, we performed a simple test to get an idea of possible temperature effects on the instrument. We watered the three MPS-1 (\#1, 2, and 3) to a certain $\psi_{\mathrm{m}}$ and sealed them with thin rubber caps to avoid evaporation from the sensor ceramics. Sensor output at a temperature of $24^{\circ} \mathrm{C}$ in the air-conditioned lab, at $6^{\circ} \mathrm{C}$ in a climatic chamber, again $24^{\circ} \mathrm{C}, 6^{\circ} \mathrm{C}$ and $24^{\circ} \mathrm{C}$ was recorded, where each temperature condition was triply measured with one hour time interval in between. This added up to $3 \times 3$ readings for $24^{\circ} \mathrm{C}$ and $2 \times 3$ readings for $6^{\circ} \mathrm{C}$ for each sensor. Moreover we measured in tap water at $24^{\circ} \mathrm{C}$ (only one reading) in two ways, submerging only the ceramic discs of the sealed sensors and the whole sensor.

\subsubsection{Soil-Specific Calibration}

The MPS-1 were coupled with the three HP sensors (pairs HP 1-MP 1, HP 2-MP 2, and HP 3-MP 3) and installed in a $6 \mathrm{~cm}$ layer of $2 \mathrm{~mm}$-sieved loam soil (33\% sand, 46\% silt and 21\% clay, USDA texture) filled into a small plastic box $(16 \mathrm{~cm} \times 26 \mathrm{~cm})$. The topsoil material had been taken a few meters apart from the lysimeter cited above. Soil and its packing in the box were similar to the calibration procedure of Nolz et al. [20]. The rods of the Hydra Probes with a length of $57 \mathrm{~mm}$ were completely inserted into the soil vertically, measuring the entire depth of the layer. The MPS-1 sensors were bedded into the wetted soil in a horizontal position with the center of the ceramic disks with a diameter of $3.2 \mathrm{~cm}$ in the middle of the soil layer. Considering the thickness of the soil layer of $6 \mathrm{~cm}$, the disc was covered on top and at the bottom at least $1.4 \mathrm{~cm}$. Distances between the probes were $<10 \mathrm{~cm}$. After initial wetting and sensor installation the soil had time to dry via evaporation at laboratory conditions (air temperature: $18^{\circ} \mathrm{C}$ to $22^{\circ} \mathrm{C}$, relative humidity: $60 \%$ to $70 \%$ ), and to consolidate. Since the Hydra Probe responds to the average water content within the sensing volume-independent of the distribu- 
tion of water within that volume [24]—we could neglect the influence of the vertical water content distribution in the soil layer on average $\theta$ determined with the calibration equation. After the initial wetting-drying-cycle, three more cycles were initiated for which $\psi_{\mathrm{m}}, \varepsilon_{\mathrm{R}, \mathrm{TC}}$, and $T_{\mathrm{s}}$ were measured continuously. Wetting to full saturation was done gradually within few hours from the bottom, so that air had time to escape from the soil. Dry bulk density and water content for sensor calibration were determined by means of four $35 \mathrm{~cm}^{3}$ core samples taken during the third drying-cycle at four different soil moisture conditions from wet to dry. The height of the samples comprised the full thickness of the soil layer, their dry bulk density was $\rho_{\mathrm{d}}=(1.32 \pm 0.05) \mathrm{g} \cdot \mathrm{cm}^{-3}$. Water content $\theta$ was determined by weighing each sample, drying at $105^{\circ} \mathrm{C}$ until mass remained constant, weighing again, and dividing the volume of water by the total sample volume. $\varepsilon_{\mathrm{R}, \mathrm{TC}}$-readings from the 3 Hydra Probes were averaged for each $\theta$ step and the parameters $A$ and $B$ of Equation (2) were fitted by minimizing the sum of squared deviations between volumetric water content from soil sampling and full submersion in water (5 points) and the function values $\theta\left(\varepsilon_{\mathrm{R}, \mathrm{TC}}\right)$ with a standard software (Table Curve 2D v5.0).

\subsection{Experimental Setup in the Field}

After the laboratory experiments, the three sensor pairs were installed 2011 in the upper soil layer of a large weighing lysimeter [25] after harvest of spring barley from August 18 (day of year DOY 230) to November 21 (DOY 324). Soil texture was loam with $28 \%$ sand, $49 \%$ silt and $23 \%$ clay; dry bulk density determined from three $200 \mathrm{~cm}^{3}$ core samples taken nearby was $\rho_{\mathrm{d}}=(1.36 \pm 0.16) \mathrm{g} \cdot \mathrm{cm}^{-3}$. In order to get a well-defined measuring zone of the topsoil layer, the Hydra Probes were pushed into the undisturbed soil vertically, measuring from soil surface to a depth of $57 \mathrm{~mm}$ (length of sensor rods). In that way they can be used for monitoring, but also for manual measurements along transects, e.g. to determine near-surface soil water dynamics of different tillage systems, or to determine spatial variability of soil water content. Generally, inserting the rods downwards is not typical for field studies, because the large head of the sensor shields the soil below from precipitation, and it may disturb evaporative and soil heat fluxes. However, vertical placement is applied for certain tasks focusing on water content in the topsoil layer [8] [12]. For the MPS-1 a vertical slot of few millimeters thickness was made with a knife with a rounded blade and soil was wetted. The sensors were put into the prepared slot and the soil was carefully compacted by hand, aiming at a proper contact between the soil and the sensor material without disturbing the structure of the surrounding soil. The center of the ceramic disks rested at a depth of $3 \mathrm{~cm}$. Distances between each Hydra Probe and the respective MPS-1 were more or less $10 \mathrm{~cm}$, and the sensor pairs were installed $<1 \mathrm{~m}$ apart. Soil water content and matric potential changed under natural conditions due to rainfall $R$ and evaporation $E$, determined daily from lysimeter measurements [25]. Several wetting-drying-periods were monitored by continuous measurements of $\psi_{\mathrm{m}}$ and $\varepsilon_{\mathrm{R}, \mathrm{TC}}$. Due to loss of Hydra Probe temperature readings, soil temperature data $T_{\mathrm{s}}$ in $5 \mathrm{~cm}$ depth $(-5 \mathrm{~cm})$ and air temperature $T_{\mathrm{a}} 5 \mathrm{~cm}$ above ground $(+5 \mathrm{~cm})$ were taken from separate temperature sensors a few meters distant.

\section{Results and Discussion}

\subsection{Inter-Sensor Variation in the Laboratory}

Hydra-Probe (HP) readings of $\varepsilon_{\mathrm{R}, \mathrm{TC}}$ in air at $T=24^{\circ} \mathrm{C}$ are shown in Table 3. Standard deviations $S D$ of repeated measurements representing precision were equal or smaller than the sensor specification of \pm 0.5 (Table 1 ). The inter-sensor variation of the readings in water were within \pm 0.3 , thus also smaller than 0.5 . Only the readings of the three sensors in air had a variation in the order of \pm 1 (Table 3). However, using a default calibration such a difference would result in a different water content of $\pm 0.03 \mathrm{~m}^{3} \cdot \mathrm{m}^{-3}$ in the dry range, which is of the same magnitude as the measurement accuracy specified by the manufacturer (Table 3). Under wet conditions $\varepsilon_{\mathrm{R}, \mathrm{TC}}$-variation of \pm 1 is negligible.

Table 3. Hydra Probe readings of $\varepsilon_{\mathrm{R}, \mathrm{TC}}$ at $T=24^{\circ} \mathrm{C}$ in air and water (mean \pm standard deviation).

\begin{tabular}{ccc}
\hline Sensor \# & Air & Water \\
\hline HP 1 & $0.2 \pm 0.06$ & $81.2 \pm 0.42$ \\
HP 2 & $-0.7 \pm 0.00$ & $81.0 \pm 0.50$ \\
HP 3 & $1.3 \pm 0.06$ & $81.4 \pm 0.21$ \\
\hline
\end{tabular}


The three wetting-drying cycles in the soil box lasted 20, 30, and 20 days, respectively (Figure 1). The sensors reacted immediately on wetting; after start of the wetting phase it took several hours until the readings reached their maximum. Although all cables were fixed to the box, measurements were sensitive to disturbances that were accidentally induced by touching the cables or moving the box, e.g. on day after start (DAS) 8 and 64 . Readings of the three Hydra Probes were between $\varepsilon_{\mathrm{R}, \mathrm{TC}}=23$ and 27 at saturation and between 4 and 6 at dry conditions (Figure 1(a)). SD ranged from 2.8 to 0.6 , which was considerably larger than the variations measured both in air and water (Figure 1). Apparently, the variations did not arise from the sensors themselves, but from soil conditions such as fine cracks, air gaps within the measuring area of a sensor, or heterogeneous water distribution. Since $S D$ was greater after wetting and decreased successively during drying (Figure 1(b)), structural soil heterogeneities such as cracks or macropores appeared to have a greater effect on inhomogeneous water distribution at or near saturation. We concluded that the differences between replications were rather due to soil characteristics than sensor variability. Hence, we decided to determine a common (soil-specific) calibration function for all three Hydra Probes for both laboratory and field application.

The MPS-1 reacted also immediately to wetting (Figure 1(c)). Sensor output ranged from $750 \mathrm{mV}$ to $770 \mathrm{mV}$ at saturation and from $560 \mathrm{mV}$ to $580 \mathrm{mV}$ at dry conditions. In total, $S D$ ranged from $12 \mathrm{mV}$ to $5 \mathrm{mV}$. In wet soil MPS-1 readings needed some time to approximate and reach equilibrium with soil water. $S D$ decreased for a few days after wetting (Figure 1(d)). During this phase sensor output was not entirely reliable. In the course of the subsequent drying the output values decreased continuously to a certain value-apparently representing the measuring range - and then decreased only slightly or even became larger again. At the same time the readings diverged, thus $S D$ became larger (this trend is contrary to Hydra Probe readings as mentioned above). The effect can be explained through the pore-size distribution of the sensor ceramics, which was obviously optimized for a certain measuring range, hence both hydraulic contact and equilibrium status between sensor and soil is not guaranteed anymore.

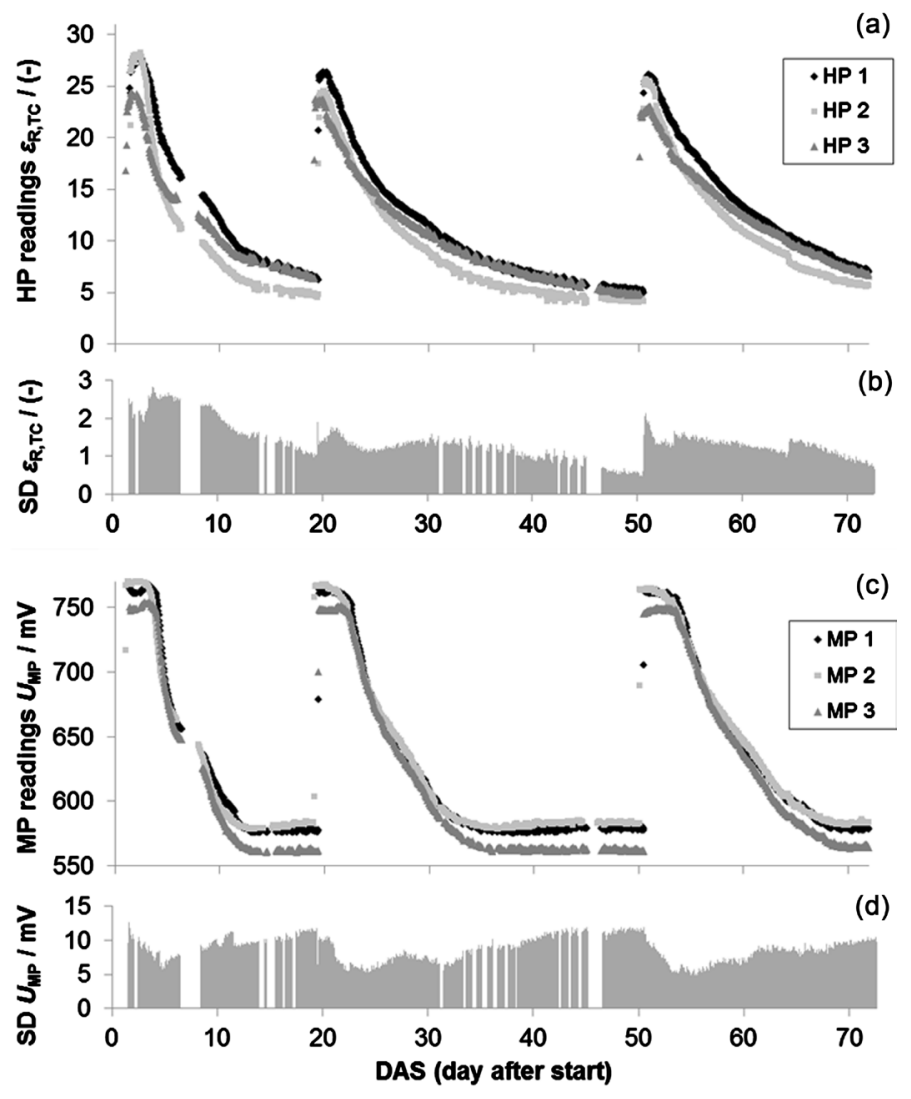

Figure 1. Sensor readings during the laboratory experiment from (a) three Hydra Probes (HP1, HP2 and HP3) with (b) standard deviation (SD), and readings from (c) MPS-1 with (d) standard deviation. 


\subsection{Sensor Calibration}

Fitting the average readings of the three Hydra Probe to the respective sampled soil water content $\theta_{\text {sample }}$ by means of Equation (2) resulted in $A=0.1382$ and $B=-0.2426$. The resultant soil calibration is similar to the recommended factory calibration for silt loam for A-horizons with $A=0.1226$ and $B=-0.1903$ [23] (Figure 2(a)), which is assumed to provide good performance in many mineral soils [15]. The calibrated water content $\theta_{\mathrm{HP} 1}$ overestimated $\theta_{\text {sample, }}$, while $\theta_{\mathrm{HP} 2}$ underestimated and $\theta_{\mathrm{HP} 3}$-values were in between (Figure 2(b)). However, RMSE was $0.022 \mathrm{~m}^{3} \cdot \mathrm{m}^{-3}$ and all $\theta$-values differed less from $\theta_{\text {sample }}$ than the specified accuracy range of \pm 0.03 $\mathrm{m}^{3} \cdot \mathrm{m}^{-3}$ [21] apart from one, deviating $0.039 \mathrm{~m}^{3} \cdot \mathrm{m}^{-3}$. With the standard calibration for silt loam RMSE would be $\pm 0.025 \mathrm{~m}^{3} \cdot \mathrm{m}^{-3}$ and 3 values would lie outside $\pm 0.03 \mathrm{~m}^{3} \cdot \mathrm{m}^{-3}$.

Figure 3 shows calibration functions of the utilized MPS-1 for a similar soil according to Nolz et al. [20]. It has to be stated, however, that even by using those sensor-specific calibrations a mean relative error of $10 \%$ is supposed to remain, and that due to the form of the calibration function a small change of the sensor output causes a great change of $\psi_{\mathrm{m}}$ when the soil becomes dry.
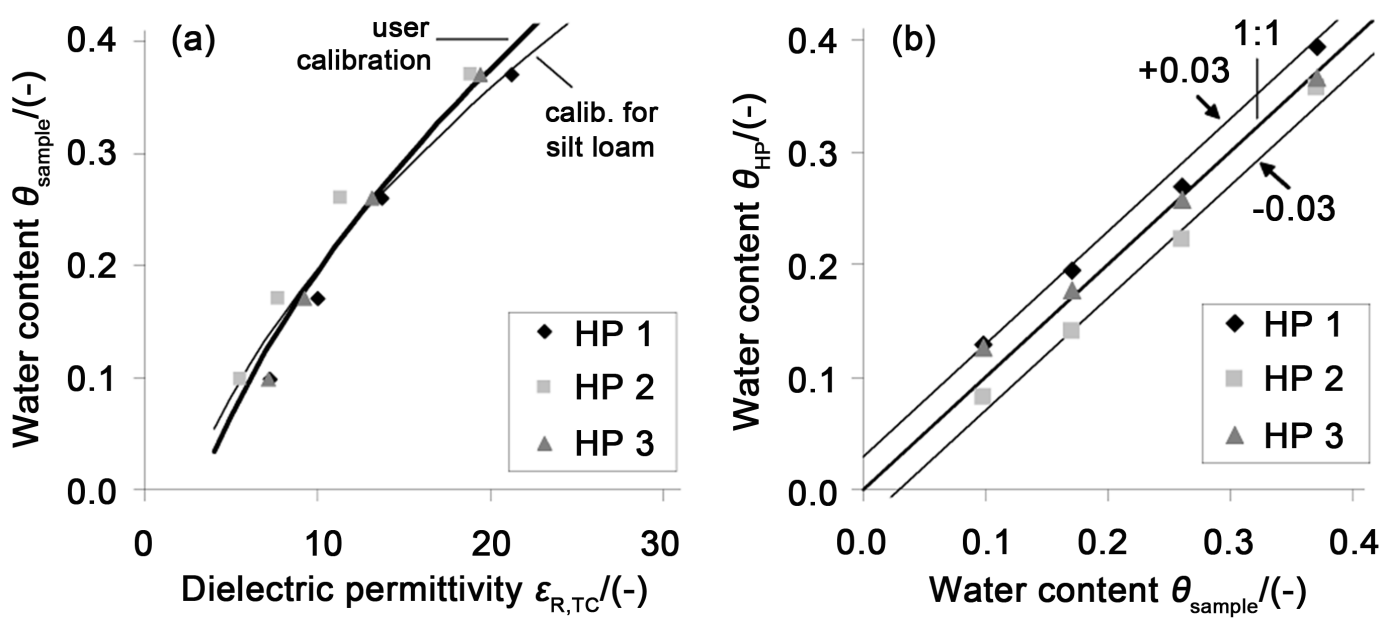

Figure 2. Hydra Probe user calibration: (a) Water content versus dielectric permittivity with calibration functions, and (b) Calibrated water content with measuring accuracy according to the manufacturer.

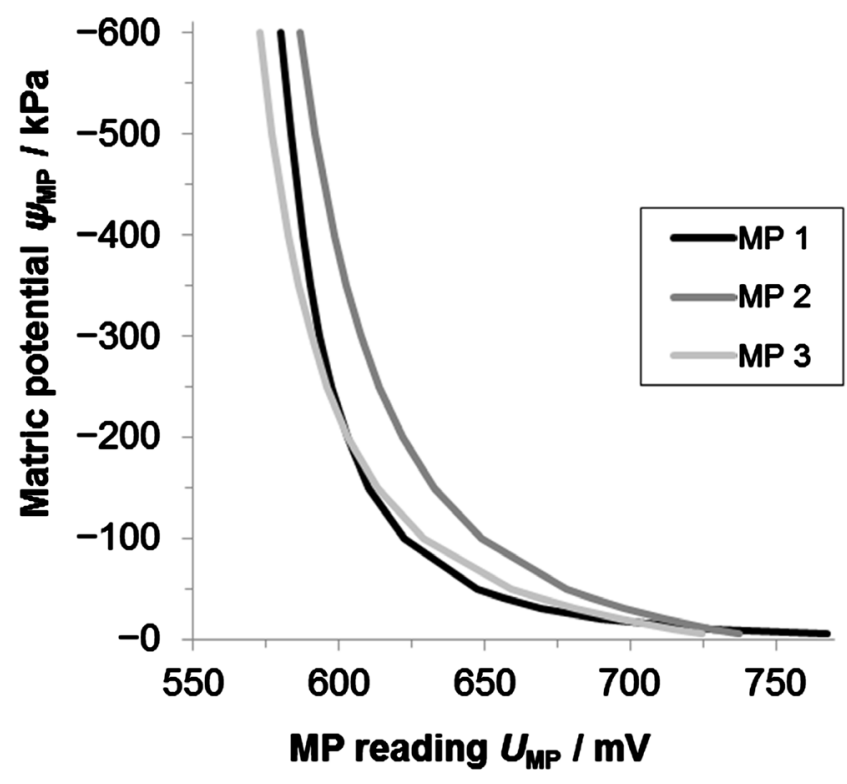

Figure 3. Sensor-specific calibration functions for the MPS-1 according to Nolz et al. [20]. 


\subsection{Soil Water Dynamics and Measuring Range in the Laboratory}

Calibrated $\theta$ ranged from $0.50 \mathrm{~m}^{3} \cdot \mathrm{m}^{-3}$ to $0.05 \mathrm{~m}^{3} \cdot \mathrm{m}^{-3}$ during the three wetting-drying phases in the laboratory (Figure 4(a)). Estimating porosity $n$ via the relation $n=1-\rho_{\mathrm{d}} / \rho_{\mathrm{s}}$ with $\rho_{\mathrm{d}}=1.32 \mathrm{~g} \cdot \mathrm{cm}^{-3}$ and particle density $\rho_{\mathrm{s}}=$ $2.65 \mathrm{~g} \cdot \mathrm{cm}^{-3}$ resulted in $n=0.50$. This value was not entirely reached by HP 3, maybe due to air gaps or soil compaction within the sensing volume. Under dry conditions temperature-related fluctuations became remarkable, especially from day after start (DAS) 30 to 45 (Figure 4(a)).

Each MPS-1 started with a certain $\psi_{\mathrm{m}}$ value between zero and $-6 \mathrm{kPa}$. However, these measurements were not consistent, because in some cases the values changed with decreasing water content, while in other cases they did not (data not shown). Since it seemed rather impractical to define a specific starting point for each MPS-1, we decided to neglect readings larger than $-10 \mathrm{kPa}$. Apparently, this makes the sensor unsuitable for measuring dominant flow processes such as infiltration. Nevertheless, measuring range depends on pore-size distribution within the sensor ceramic; hence, single sensors might be appropriate to measure also between zero and $-10 \mathrm{kPa}$. In dry soil all sensors delivered values below the specified minimum value of $-500 \mathrm{kPa}$ (down to $-1.2 \mathrm{MPa}$ ). But these data were also not reliable, because after a sensor reached its limit, the output value decreased to some extent, and fluctuated correlating with temperature around an individual level (Figure 4(b)). Soil temperature ranged from $17^{\circ} \mathrm{C}$ to $27^{\circ} \mathrm{C}$ with distinct diurnal variations (Figure 4(c)).

\subsection{Soil Water Dynamics and Measuring Range in the Field}

During the field experiment soil water content and matric potential changed evidently due to several rainfall events and considerable evaporation (Figure 5). We measured a range for $\theta$ from $0.45 \mathrm{~m}^{3} \cdot \mathrm{m}^{-3}$ to $0.17 \mathrm{~m}^{3} \cdot \mathrm{m}^{-3}$ (Figure 5(a)), thus smaller than at laboratory experiment. $\theta$ values from HP 1 and HP 2 were similar near saturation, but diverged until HP 1 delivered smaller values than HP 2 when getting drier. In the laboratory, on the contrary, HP 2 was always below HP 1 (Figure 4(a)), so it is evident that these differences were not caused by systematic errors from calibration. Due to a software failure there were no data from HP 3. Fluctuations of HP-readings as a result of temperature effects were distinctive, so small rainfall events, e.g. $4 \mathrm{~mm}$ on DOY 257 were hardly reflected in $\theta$-measurements. $\psi_{\mathrm{m}}$ was similarly difficult to interpret because of oscillations, espe-

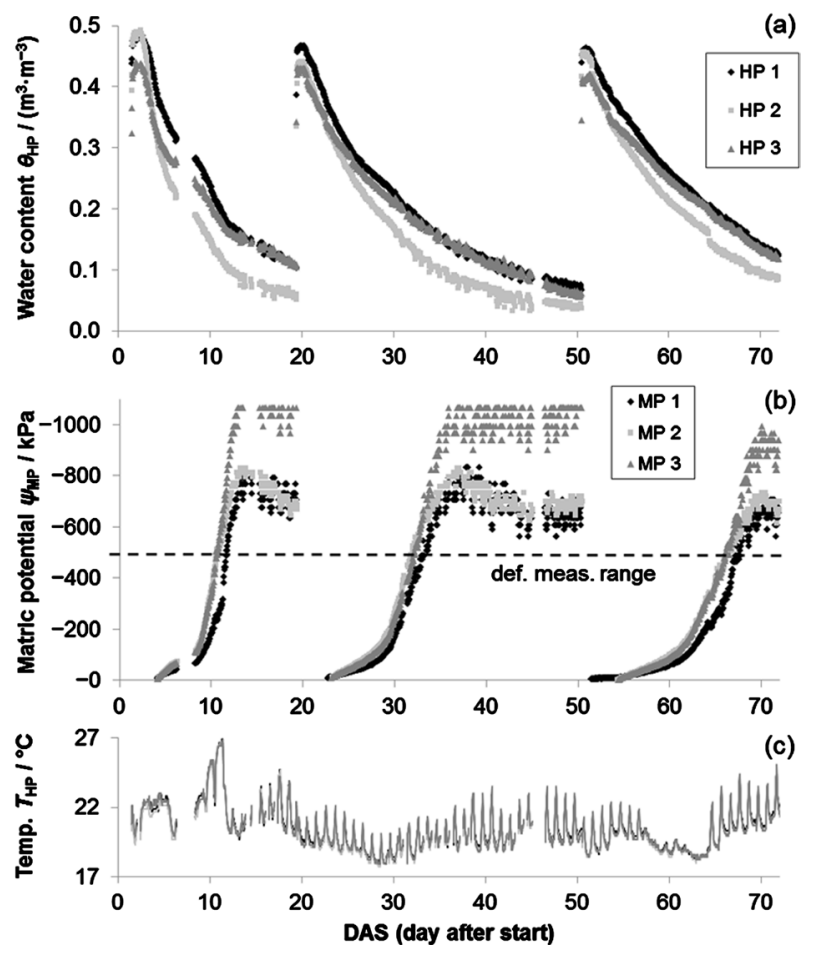

Figure 4. Soil water dynamics during the laboratory experiment. The dotted line illustrates the limit of operation specified by the manufacturer. 

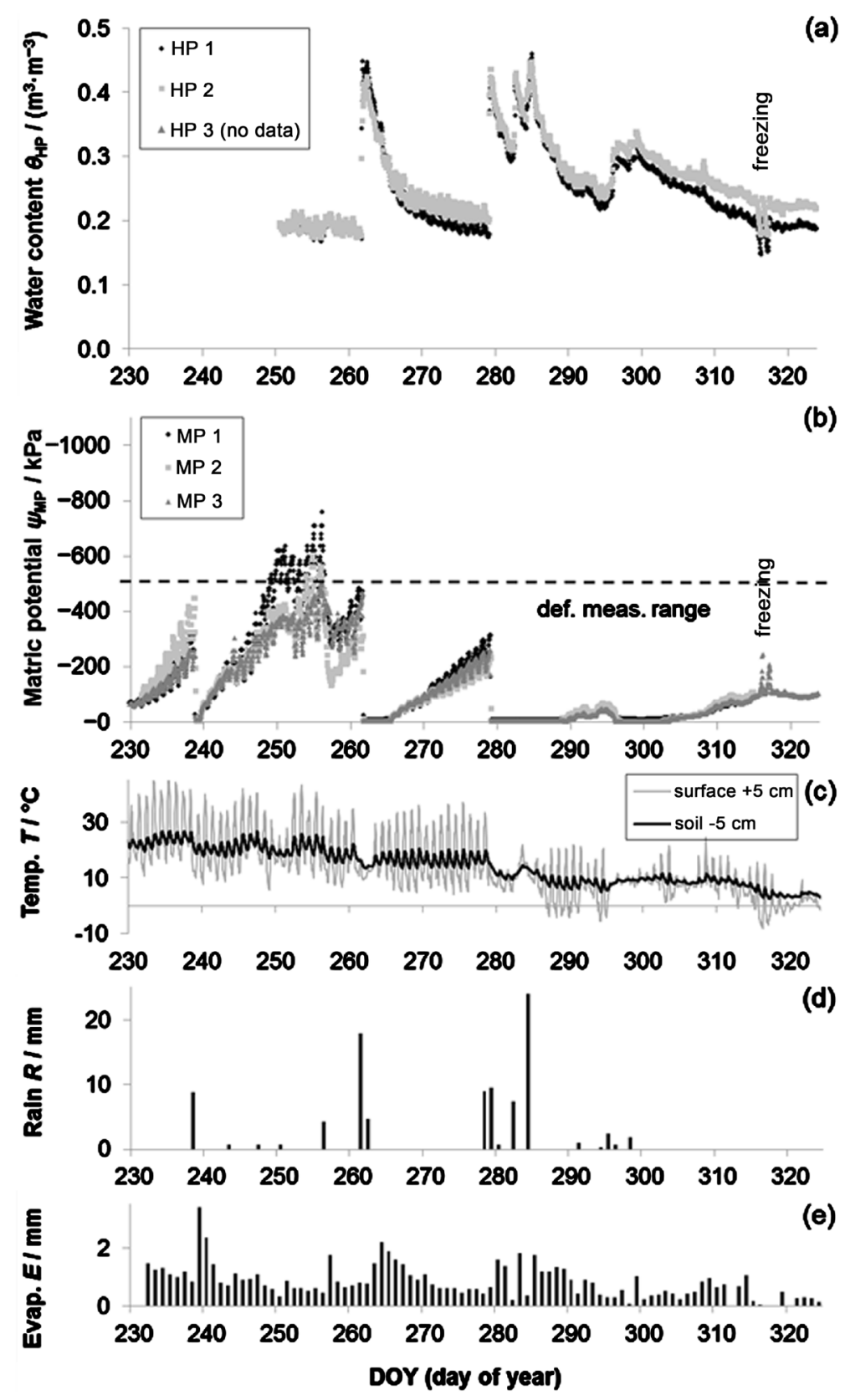

Figure 5. (a) Soil water content; (b) Matric potential; (c) Soil temperature; (d) Rainfall and (e) Evaporation during the field experiment.

cially when the soil got dry, e.g. from DOY 250 to 260 (Figure 5(b)). Compared to the laboratory results, the range of $\psi_{\mathrm{m}}$ was generally smaller with a minimum of $-750 \mathrm{kPa}$. Under wet conditions MPS-1 provided evident $\psi_{\mathrm{m}}$-readings only when greater than $-10 \mathrm{kPa}$, which corresponded well with the findings from the laboratory experiment. While from DOY 230 to 240 MP 2 gave the smallest $\psi_{\mathrm{m}}$, MP 1-values were lesser than the others from DOY 245 to 255. Similar to the $\theta$ measurements, the differences were not supposed to be related to sensor calibration, but rather to soil heterogeneity and inhomogeneous water distribution. On DOY 316 and 317 readings of both sensors (measuring from zero to $-6 \mathrm{~cm}$ ) were obviously incorrect due to freezing.

Soil temperature in $5 \mathrm{~cm}$ depth (soil $-5 \mathrm{~cm}$ ) was between $2^{\circ} \mathrm{C}$ and $28^{\circ} \mathrm{C}$, temperature fluctuations above ground (surface $+5 \mathrm{~cm}$ ) were substantially larger. This illustrates the challenging conditions under which the sensors were operated (Figure 5(c)). 


\subsection{Temperature Effects in Laboratory and in the Field}

Generally, temperature effects are related to both sensor electronics and soil hydraulic properties, making temperature compensation a very complex problem [17]. As mentioned above, we used Hydra-Probe readings with a temperature correction from zero to $35^{\circ} \mathrm{C}\left(\varepsilon_{\mathrm{R}, \mathrm{TC}}\right)$ [15] [23]. Table 4 exemplifies calculated $\varepsilon_{\mathrm{R}, \mathrm{TC}}$ values (Equation (1)) for different $\theta$ and temperature that occurred in laboratory as well as in field. One can see that the maximum difference between zero and $35^{\circ} \mathrm{C}$ was $0.01 \mathrm{~m}^{3} \cdot \mathrm{m}^{-3}$ at dry and $0.03 \mathrm{~m}^{3} \cdot \mathrm{m}^{-3}$ at wet conditions, giving a slope $\Delta \theta / \Delta T$ of $0.0003 \mathrm{~m}^{3} \cdot \mathrm{m}^{-3} \cdot{ }^{\circ} \mathrm{C}^{-1}$ and $0.0009 \mathrm{~m}^{3} \cdot \mathrm{m}^{-3} \cdot{ }^{\circ} \mathrm{C}^{-1}$, respectively. Seyfried and Grant [16] reported, that-with a change from $5^{\circ} \mathrm{C}$ to $45^{\circ} \mathrm{C}$-the instrument effect was greater than $0.01 \mathrm{~m}^{3} \cdot \mathrm{m}^{-3}$ in dry soil, and much lesser at greater $\theta$. For a $20^{\circ} \mathrm{C}$ change they found differences less than $0.01 \mathrm{~m}^{3} \cdot \mathrm{m}^{-3}$ for all $\theta$. In contrast to measurements in water, where $\theta$ decreases when temperature increases, temperature effects in soils are more complex. Seyfried and Grant [16] found a linear temperature response in different soils of $\pm 0.03 \mathrm{~m}^{3} \cdot \mathrm{m}^{-3}$ for temperatures ranging from $5^{\circ} \mathrm{C}$ to $45^{\circ} \mathrm{C}$, and thus a slope $\Delta \theta / \Delta T$ from $-0.0007 \mathrm{~m}^{3} \cdot \mathrm{m}^{-3} \cdot{ }^{\circ} \mathrm{C}^{-1}$ to $0.0007 \mathrm{~m}^{3} \cdot \mathrm{m}^{-3} \cdot{ }^{\circ} \mathrm{C}^{-1}$. Comparing this slope with those above derived from the values in Table 4 indicates that the temperature compensation (Equation (1)) accounts for both instrument and soil temperature effects.

In contrast to findings of Malazian et al. [19], the MPS-1 showed large temperature sensitivity during our experiments. Table 5 summarises the measurements with the sealed sensors (no uptake or release of water and water vapor) at different temperatures. The sensor output at $24^{\circ} \mathrm{C}$ was relatively stable during the whole measuring period, but sensor readings at $6^{\circ} \mathrm{C}$ were less consistent. While sensors \#1 and \#2 delivered substantially greater values (20\% and $60 \%$ ) at the smaller temperature, sensor \#3 delivered slightly smaller values (Table 5). Partly submerging of the sealed sensor into water had no effect on the sensor output, but when completely under water, the sensor readings at once decreased evidently (Table 5). Since there was no exchange of water, the readings were likely influenced by the surrounding water. Another effect was that touching the sensor body decreased sensor readings within an instant, too. Evaluating these effects is beyond the scope of this paper, but it seems that the electromagnetic field of the sensor expands beyond sensor ceramics, which is problematic regarding calibration and data interpretation.

Looking thoroughly on the curves of Figure 4(a) (box experiment), $\theta$ showed oscillations of $\pm 0.03 \mathrm{~m}^{3} \cdot \mathrm{m}^{-3}$ when the soil became dry (e.g. near DAS 40). This can neither be explained by instrument nor by soil temperature effects as discussed at the beginning of this section. The corresponding $\psi_{\mathrm{m}}$ values varied considerably \pm 100 $\mathrm{kPa}$, but were already out of the defined measuring range of the sensors (Figure 4(b)). Figure 6 displays details of Figure 4 and Figure 5 in order to illustrate and compare temperature effects in the laboratory and in the field. As expected, Hydra Probe as well as MPS-1 measurements in the laboratory showed no substantial fluctuations in the wet range, with a soil temperature between $18^{\circ} \mathrm{C}$ and $22^{\circ} \mathrm{C}$ (Figure 6(a)).

Table 4. Hydra Probe: temperature corrected water content $\theta\left(\varepsilon_{\mathrm{R}, \mathrm{TC}}\right)$ for different water contents and temperatures $T$.

\begin{tabular}{cccc}
\hline $0{ }^{\circ} \mathrm{C}$ & $15^{\circ} \mathrm{C}$ & $25^{\circ} \mathrm{C}$ & $35^{\circ} \mathrm{C}$ \\
\hline & \multicolumn{2}{c}{$\theta\left(\varepsilon_{\mathrm{R}, \mathrm{TC}}\right) /\left(\mathrm{m}^{3} \cdot \mathrm{m}^{-3}\right)$} & \\
\hline 06 & 0.07 & 0.07 & 0.07 \\
0.19 & 0.19 & 0.20 & 0.20 \\
0.37 & 0.38 & 0.38 & 0.39 \\
0.50 & 0.51 & 0.52 & 0.53 \\
\hline
\end{tabular}

Table 5. $\psi_{\mathrm{m}}$-values of the sealed MPS-1 at different temperatures $T$.

\begin{tabular}{cccc|}
\hline$T /{ }^{\circ} \mathrm{C}$ & 24 & 6 & 24 \\
\hline Sensor exposed to & Air & Air & Water (totally submerged) \\
\hline Sensor \# & & $\psi_{\mathrm{m}} / \mathrm{kPa}$ & 182 \\
\hline 1 & $435 \pm 16$ & $512 \pm 25$ & 240 \\
2 & $482 \pm 34$ & $787 \pm 31$ & 134 \\
\hline 3 & $386 \pm 17$ & $349 \pm 36$ & \\
\hline
\end{tabular}




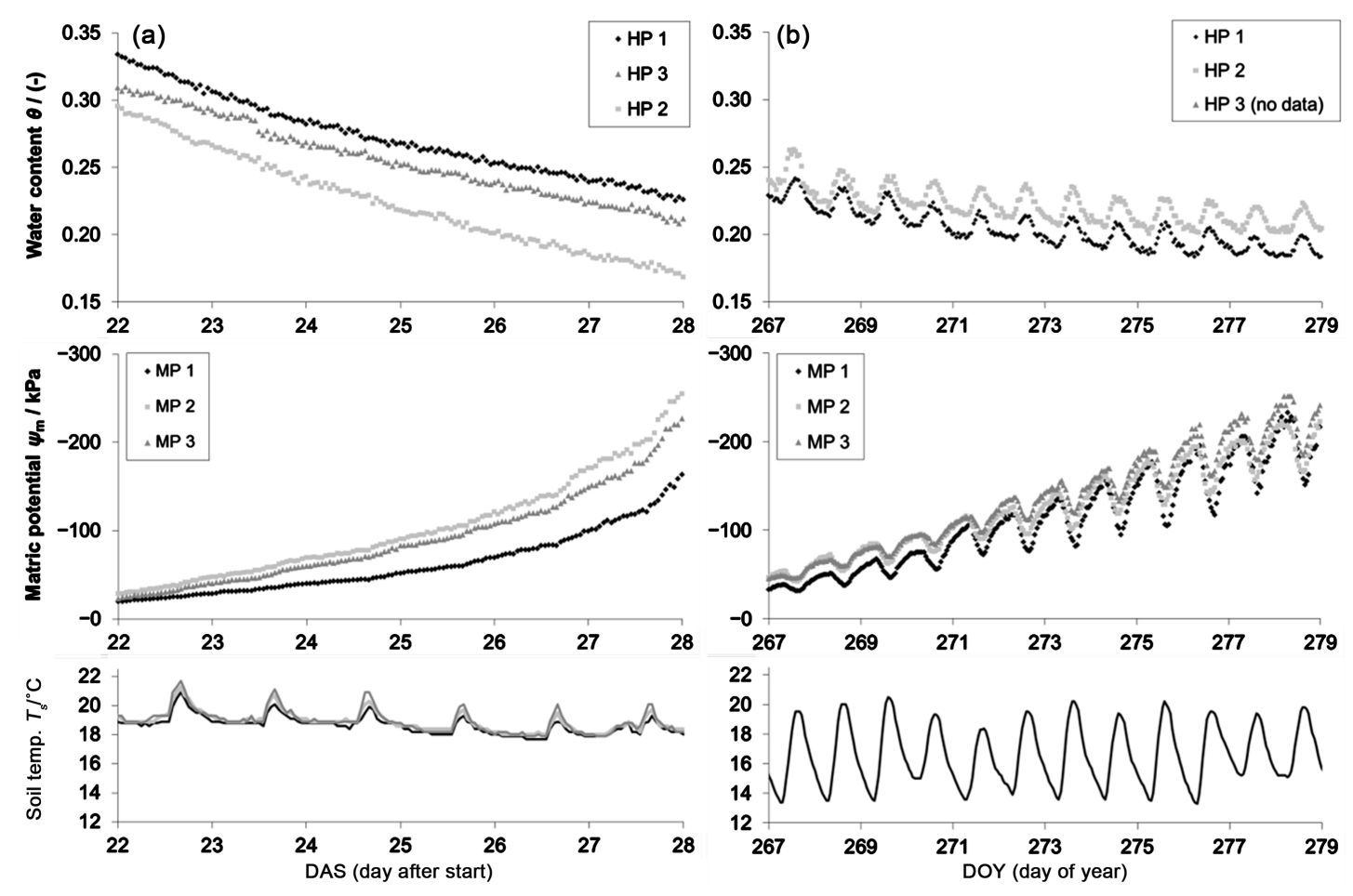

Figure 6. Soil water dynamics and soil temperature (a) in laboratory; and (b) in the field.

During the field experiment day-night-fluctuation of soil temperature in a selected period was between $13^{\circ} \mathrm{C}$ and $20^{\circ} \mathrm{C}$ (Figure 6(b)). Apparently, temperature-driven variations of soil water content and matric potential were predominant under field conditions. Despite temperature correction, $\theta$ changed during a day around \pm 0.03 $\mathrm{m}^{3} \cdot \mathrm{m}^{-3}$ in the wet range, which is larger than any temperature effect estimated from $\varepsilon_{\mathrm{R}}$ temperature response. Regarding fluctuations in $\psi_{\mathrm{m}}$-data it was impossible to separate real soil water dynamics from instrument temperature effects without detailed knowledge about the latter. Anyway, the fluctuations of $\psi_{\mathrm{m}}$ were greater than $30 \%$ and temperature differences were smaller (Figure 6(b)) compared to the MPS-1 temperature test (Table 5). Consequently, the shown variations arose likely to the most part from temperature-driven changes of soil water content itself [4] [26]. The minimum daily $\theta$ and its corresponding maximum $\psi_{\mathrm{m}}$ usually occurred at the minimum temperature at about 7 a.m., while vice versa maximum $\theta$ and minimum $\psi_{\mathrm{m}}$ occurred at the maximum temperature at about $3 \mathrm{p}$.m. (Figure 6(b)). The daily mean values of $\theta$ and $\psi_{\mathrm{m}}$ were typically represented by values measured between 10 and $11 \mathrm{a} . \mathrm{m}$. This has to be taken into account when soil water is not monitored continuously. Apart from that, further studies are required with respect to water and water vapor transport to explain the observations. Another open question addresses the temperature sensitivity of the MPS-1.

\section{Conclusions}

Performance of Hydra Probe water content sensors and MPS-1 matric potential sensors was tested in a nearsurface soil layer in the laboratory and under natural conditions in the field.

A common soil-specific calibration function was assessed for the Hydra Probes, but also a default calibration from literature was suitable. Measurement accuracy was $\pm 0.03 \mathrm{~m}^{3} \cdot \mathrm{m}^{-3}$, which is in accordance with the manufacturer specification. Sensor-to-sensor variation was considerable, but within the accuracy range. Generally, Hydra Probes measure from dry to saturated conditions. Soil water content ranged from 0.50 to $0.05 \mathrm{~m}^{3} \cdot \mathrm{m}^{-3}$ during the laboratory experiment and from 0.45 to $0.17 \mathrm{~m}^{3} \cdot \mathrm{m}^{-3}$ in the field. Temperature sensitivity was minor in laboratory, but substantial in field. However, in natural environment the diurnal fluctuations of soil water content with its minimum at the minimum temperature and vice versa arose likely to the most part from temperature-driven changes of soil water content.

Sensor-specific calibrations from a previous study were used to reduce inter-sensor variation of MPS-1. Measurement accuracy can be expressed by a mean relative error of $10 \%$. According to the manual the applica- 
tion range of matric potential values is from -10 to $-500 \mathrm{kPa}$. MPS-1 delivered also readings outside this range, but they were not reliable. Sensor electronics of the MPS-1 were prone to temperature changes, and sensor output was affected by the surrounding area. In this regard, further studies are recommended. Fluctuations of matric potential in the field were major with an opposite trend to water content. Generally, soil water dynamics in the field was well described from both sensor types, but data showed substantial temperature-driven fluctuations that made data interpretation difficult to some extent. The daily mean values of water content and matric potential were typically represented by values measured between 10 and 11 a.m.

\section{Acknowledgements}

We thank Karl Haigner, Andreas Hartner, and Christoph Schoenher for their work in the laboratory and in the field, and the staff members of Adcon Telemetry GmbH, Klosterneuburg for support. The cooperation with Dr. Marek Rodny from IH SAS was supported by Project APVV 0139-10.

\section{References}

[1] Huntington, T.G. (2006) Evidence for Intensification of the Global Water Cycle: Review and Synthesis. Journal of Hydrology, 319, 83-95. http://dx.doi.org/10.1016/j.jhydrol.2005.07.003

[2] Mohanty, B.P., Shouse, P.J. and van Genuchten, M.T. (1998) Spatio-Temporal Dynamics of Water and Heat in a Field Soil. Soil and Tillage Research, 47, 133-143. http://dx.doi.org/10.1016/S0167-1987(98)00084-1

[3] Monteith, J.L. and Unsworth, M.H. (2008) Principles of Environmental Physics. 3rd Edition, Academic Press, New York, 418.

[4] Cahill, A.T. and Parlange, M.B. (1998) On Water Vapor Transport in Field Soils. Water Resources Research, 34, 731739. http://dx.doi.org/10.1029/97WR03756

[5] Aydin, M., Yang, S.L., Kurt, N. and Yano, T. (2005) Test of a Simple Model for Estimating Evaporation from Bare Soils in Different Environments. Ecological Modelling, 182, 91-105. http://dx.doi.org/10.1016/j.ecolmodel.2004.07.013

[6] Flerchinger, G.N., Sauer, T.J. and Aiken, R.A. (2003) Effects of Crop Residue Cover and Architecture on Heat and Water Transfer at the Soil Surface. Geoderma, 116, 217-233. http://dx.doi.org/10.1016/S0016-7061(03)00102-2

[7] Ersahin, S. and Brohi, A.R. (2006) Spatial Variation of Soil Water Content in Topsoil and Subsoil of a Typic Ustifluvent. Agricultural Water Management, 83, 79-86. http://dx.doi.org/10.1016/j.agwat.2005.09.002

[8] Lambot, S., Slob, E., Chavarro, D., Lubczynski, M. and Vereecken, H. (2008) Measuring Soil Surface Water Content in Irrigated Areas of Southern Tunisia Using Full-Waveform Inversion of Proximal GPR Data. Near Surface Geophysics, 6, 403-410.

[9] López Riquelme, J.A., Soto, F., Suardíaz, J., Sánchez, P., Iborra, A. and Vera, J.A. (2009) Wireless Sensor Networks for Precision Horticulture in Southern Spain. Computers and Electronics in Agriculture, 68, 25-35. http://dx.doi.org/10.1016/j.compag.2009.04.006

[10] Martinez, C., Hancock, G.R., Kalma, J.D. and Wells, T. (2008) Spatio-Temporal Distribution of Near-Surface and Root Zone Soil Moisture at the Catchment Scale. Hydrological Processes, 22, 2699-2714. http://dx.doi.org/10.1002/hyp.6869

[11] Méndez-Barroso, L.A., Vivoni, E.R., Watts, C.J. and Rodríguez, J.C. (2009) Seasonal and Interannual Relations between Precipitation, Surface Soil Moisture and Vegetation Dynamics in the North American Monsoon Region. Journal of Hydrology, 377, 59-70. http://dx.doi.org/10.1016/j.jhydrol.2009.08.009

[12] Smith, A.B., Walker, J.P., Western, A.W., Young, R.I., Ellett, K.M., Pipunic, R.C., Grayson, R.B., Siriwidena, L., Chiew, F.H.S. and Richter, H. (2012) The Murrumbidgee Soil Moisture Monitoring Network Data Set. Water Resources Research, 486.

[13] Evett, S.R., Schwartz, R.C., Lascano, R.J. and Pelletier, M.G. (2010) In-Soil and Down-Hole Soil Water Sensors: Characteristics for Irrigation Management. Proceedings of 5th Decennial National Irrigation Conference, 5-8 December 2010, Phoenix.

[14] Seyfried, M.S. and Murdock, M.D. (2004) Measurement of Soil Water Content with a 50-MHz Soil Dielectric Sensor. Soil Science Society of America Journal, 68, 394-403. http://dx.doi.org/10.2136/sssaj2004.3940

[15] Seyfried, M.S., Grant, L.E., Du, E. and Humes, K. (2005) Dielectric Loss and Calibration of the Hydra Probe Soil Water Sensor. Vadose Zone Journal, 4, 1070-1079. http://dx.doi.org/10.2136/vzj2004.0148

[16] Seyfried, M.S. and Grant, L.E. (2007) Temperature Effects on Soil Dielectric Properties Measured at 50 MHz. Vadose Zone Journal, 6, 759-765. http://dx.doi.org/10.2136/vzj2006.0188 
[17] Vaz, C.M.P., Jones, S., Meding, M. and Tuller, M. (2013) Evaluation of Standard Calibration Functions for Eight Electromagnetic Soil Moisture Sensors. Vadose Zone Journal, 12. http://dx.doi.org/10.2136/vzj2012.0160

[18] Decagon Devices (2009) Dielectric Water Potential Sensor MPS-1. Operator's Manual Version 3.0. Decagon Devices, Inc., 2350 NE Hopkins Court, Pullman, WA 99163.

[19] Malazian, A., Hartsough, P., Kamai, T., Campbell, G., Cobos, D. and Hopmans, J. (2011) Evaluation of MPS-1 Soil Water Potential Sensor. Journal of Hydrology, 402, 126-134. http://dx.doi.org/10.1016/j.jhydrol.2011.03.006

[20] Nolz, R., Kammerer, G. and Cepuder, P. (2013) Calibrating Soil Water Potential Sensors Integrated into a Wireless Monitoring Network. Agricultural Water Management, 116, 12-20. http://dx.doi.org/10.1016/j.agwat.2012.10.002

[21] Stevens (2007) Hydra Probe Users Manual. Stevens Water Monitoring Systems Inc., Portland.

[22] Adcon (2013) Information on Adcon Wireless Sensor Networks. Adcon Telemetry GmbH, Klosterneuburg. http://www.adcon.at

[23] Bellingham, K. (2007) The Stevens Hydra Probe Inorganic Soil Calibrations. Stevens Water Monitoring Systems Inc., Portland. http://www.soilsensor.com/articles

[24] Loiskandl, W., Buchan, G.D., Sokol, W., Novak, V. and Himmelbauer, M. (2010) Calibrating Electromagnetic Short Soil Water Sensors. Journal of Hydrology and Hydromechanics, 58, 114-125. http://dx.doi.org/10.2478/v10098-010-0011-3

[25] Nolz, R., Kammerer, G. and Cepuder, P. (2013) Interpretation of Lysimeter Weighing Data Affected by Wind. Journal of Plant Nutrition and Soil Science, 176, 200-208. http://dx.doi.org/10.1002/jpln.201200342

[26] Rose, C.W. (1968) Water Transport in Soil with a Daily Temperature Wave. I: Theory and Experiment. Australian Journal of Soil Research, 6, 31-44. http://dx.doi.org/10.1071/SR9680031 
Scientific Research Publishing (SCIRP) is one of the largest Open Access journal publishers. It is currently publishing more than 200 open access, online, peer-reviewed journals covering a wide range of academic disciplines. SCIRP serves the worldwide academic communities and contributes to the progress and application of science with its publication.

Other selected journals from SCIRP are listed as below. Submit your manuscript to us via either submit@scirp.org or Online Submission Portal.
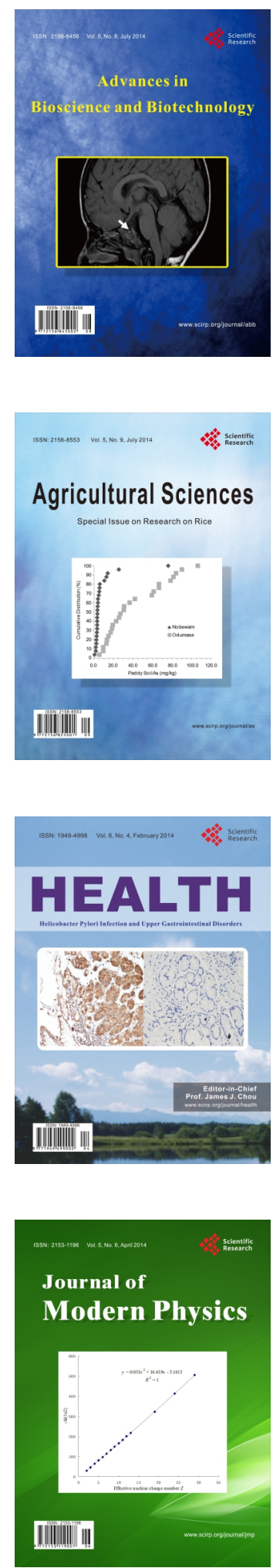
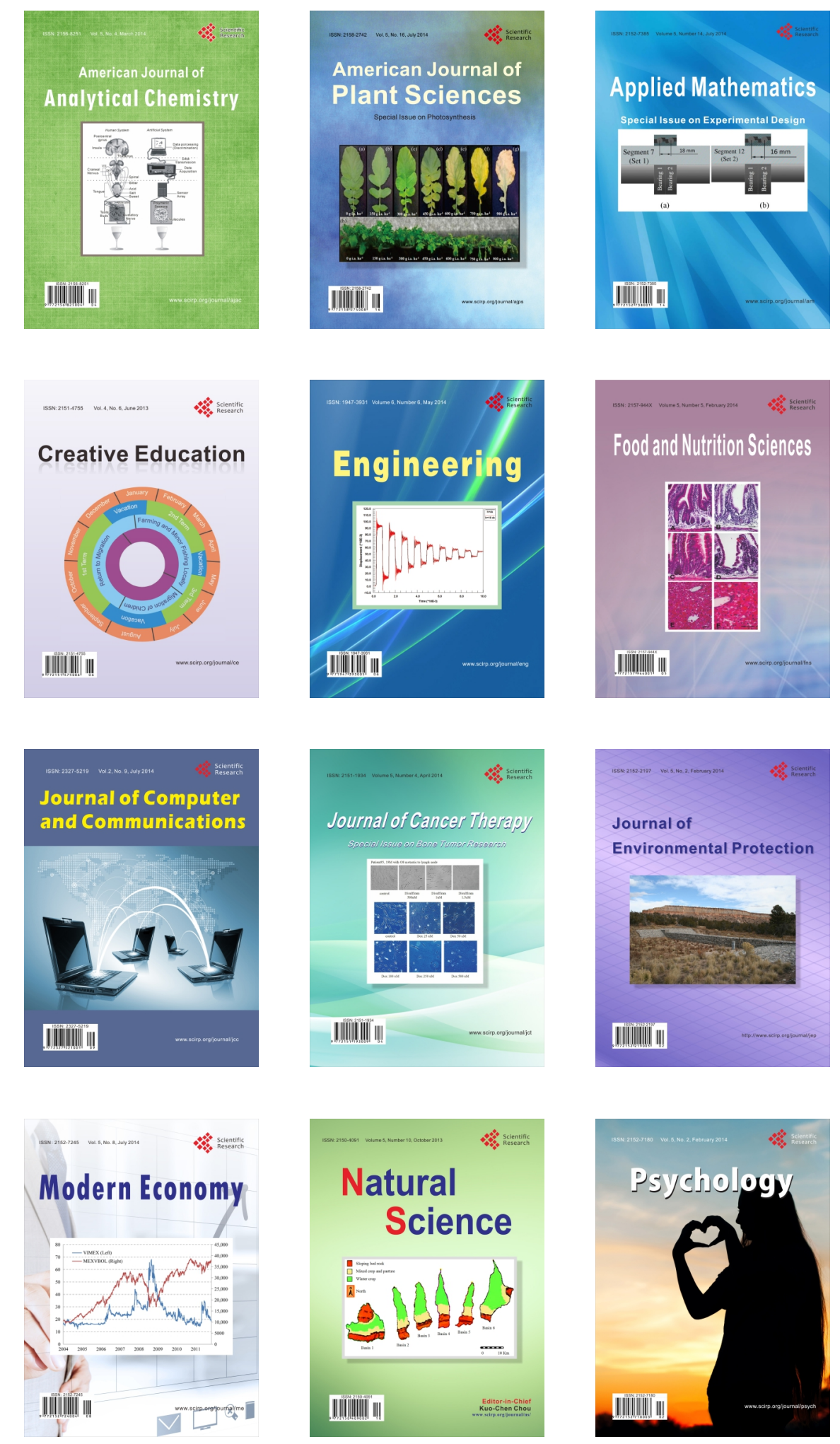